\title{
Small Scale Wind Energy Conversion Systems
}

\author{
Mostafa Abarzadeh, Hossein Madadi Kojabadi ${ }^{1}$ and Liuchen Chang ${ }^{2}$ \\ ${ }^{1}$ Sahand University of Technology \\ ${ }^{2}$ University of New Brunswick \\ ${ }^{1}$ Iran \\ ${ }^{2}$ Canada
}

\section{Introduction}

Electricity generation using wind energy has been well recognized as environmentally friendly, socially beneficial, and economically competitive for many applications. Because of crucial fossil energy resources shortage and environmental issues the wind energy is very important resource for electricity production. Small wind turbines, photovoltaic systems, full cells and pump as turbines (PAT) in small scale are main resources for distributed generation systems. Meanwhile, for remote areas wind energy beside photovoltaic system can combine as a hybrid system to provide necessary electric power of users. This system should be designed in such a way that the load demand of remote areas be provided with maximum reliability. Usually Direct coupled axial flux permanent magnet synchronous generator (AFPMSG), self-excited induction generator with gear box and permanent magnet synchronous generator(PMSG) with gear box can be used to connect to small wind turbine. In the past few years, there have been many studies on small scale wind energy conversion systems. Authors of (Jia Yaoqin et al., 2002), (Nobutoshi Mutoh et al., 2006), (T.Tafticht et al., 2006), (Ch.Patsios et al., 2008) and (M.G.Molina et al., 2008) presented maximum power point tracking(MPPT) methods for small scale wind turbines. (Etienne Audierne et al., 2009), (M.G.Molina et al., 2008), (Boubekeur Boukhezzar et al., 2005), (Md.Arifujjaman et al., 2005) and (Jan T.Bialasiewicz, 2003) described small scale wind turbine furling system and modeled small scale wind turbines.

In this chapter we reviewed the working principles, over speed, output power control and MPPT control methods of small scale wind energy conversion system.

\section{Wind turbine characteristics}

The kinetic energy of the air stream available for the wind turbine given by

$$
E=\frac{1}{2} \rho_{a} v V^{2}
$$

where $\rho_{a}$ is air density, $v$ is the volume of air available to the wind turbine rotor and $V$ is the velocity of wind stream in $\mathrm{m} / \mathrm{s}$. The air parcel interacting with the rotor per second has a cross-sectional area equal to that of the rotor $\left(A_{T}\left(m^{2}\right)\right)$ and thickness equal to the wind velocity $(V(m / s))$. Hence power of air stream available for wind turbine given by 


$$
P=\frac{1}{2} \rho_{a} A_{T} V^{3}
$$

However, wind turbine can not convert power of air stream completely. When the power stream passes the turbine, a part of its kinetic energy is transferred to the rotor and the air leaving the turbine carries the rest way. The actual power produced by wind turbine, usually, describe by power coefficient $\left(C_{P}\right) \cdot C_{P}$ is the ratio of available power from wind stream and the power transferred to wind turbine. Hence

$$
C_{P}=\frac{2 P_{T}}{\rho_{a} A_{T} V^{3}}
$$

where $P_{T}$ is the power available from wind stream. According to Betz's law, no turbine can capture more than 59.3 percent of the kinetic energy in wind. The ideal or maximum theoretical efficiency (also called power coefficient, $C_{P}$ ) of a wind turbine is the ratio of maximum power obtained from the wind to the total power available in the wind. The factor 0.593 is known as Betz's coefficient. It is the maximum fraction of the power in a wind stream that can be extracted.

The $C_{P}$ of a wind turbine depends on the profile of rotor blades, blade arrangement and setting etc. A designer would try to fix these parameters at its optimum level so as to attain maximum $C_{P}$ at a wide range of wind velocities.

The thrust force experienced by the rotor $(F)$ and rotor torque $(T)$ are given by

$$
\begin{gathered}
F=\frac{1}{2} \rho_{a} A_{T} V^{2} \\
T=\frac{1}{2} \rho_{a} A_{T} V^{2} R
\end{gathered}
$$

where $\mathrm{R}$ is the radius of the rotor. The ratio between the actual torque developed by the rotor and theoretical torque is termed as the torque coefficient $\left(C_{T}\right)$. Thus,

$$
C_{T}=\frac{2 T_{T}}{\rho_{a} A_{T} V^{2} R}
$$

where $T_{T}$ is the actual torque developed by the rotor.

The ratio between the velocity of the rotor tip and the wind velocity is termed as the tip speed ratio $(\lambda)$. The power developed by the rotor at a certain wind speed greatly depends on tip speed ratio $(\lambda)$. Thus,

$$
\lambda=\frac{R \Omega}{V}=\frac{2 \pi N R}{V}
$$

where $\Omega$ is the angular velocity and $N$ is the rotational speed of the rotor. The power coefficient and torque coefficient of a rotor vary with the tip speed ratio. The tip speed ratio is given by the ratio between the power coefficient and torque coefficient of the rotor. 


$$
\frac{C_{P}}{C_{T}}=\frac{R \Omega}{V}=\lambda
$$

The efficiency with which a rotor can extract power from the wind depends on the dynamic matching between the rotor and wind stream. The $C_{P}-\lambda$ curve will represent the rotor performance irrespective of the rotor size and site parameters. The $C_{P}-\lambda$ curve represent the performance of the turbine irrespective rotor size and site parameters.

Typical $C_{P}-\lambda$ curves for different rotors are presented in Fig.1. in general, initially the power coefficient of the turbine increases with the tip speed ratio, reaches a maximum at a typical $\lambda$, and then decreases with further increase in the tip speed ratio.

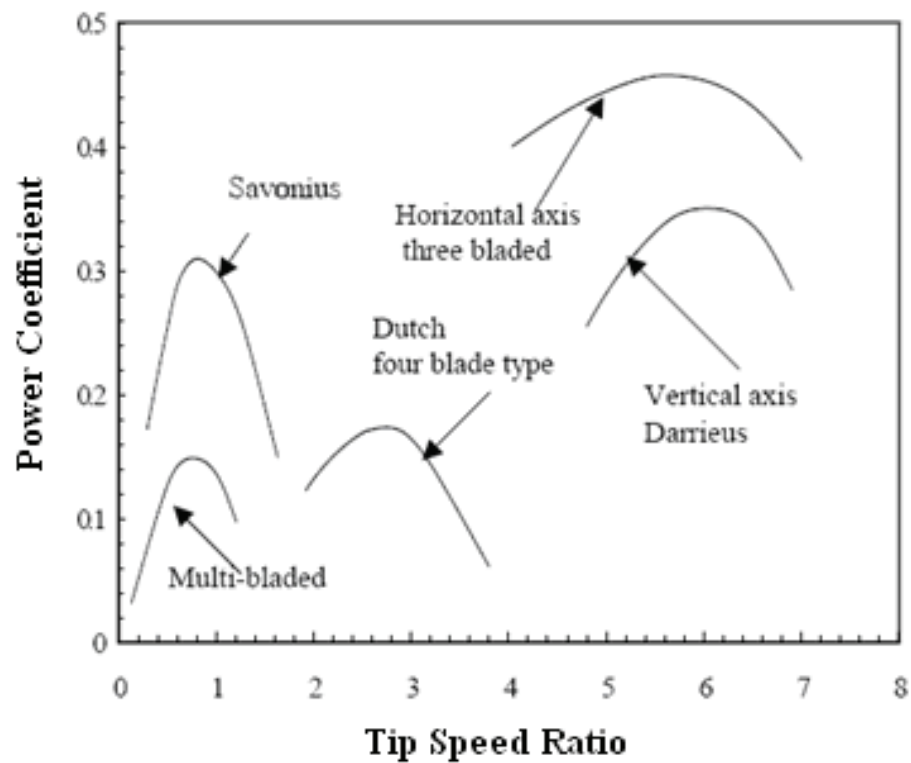

Fig. 1. Performance characteristics of wind rotors

The variations in $C_{P}$ with $\lambda$ depend on several design features of the rotor. American multi-bladed rotors show the lowest power coefficient and work at low speed ratio with the wind. However they have high solidity and hence high starting torque which make them attractive for water pumping. Two and three blade propeller turbines and the darrieus design turbine work at higher tip speed ratios. Hence they are suitable for wind electric generators.( Sathyajith Mathew)

\section{Wind energy conversion systems}

The main components of a wind turbine system are illustrated in Fig.2, including a turbine rotor, gearbox, generator, power electronic system and transformer.

Wind turbines convert the power from wind to mechanical power. It is important to be able to control and limit the converted mechanical power during higher wind speeds. The power 


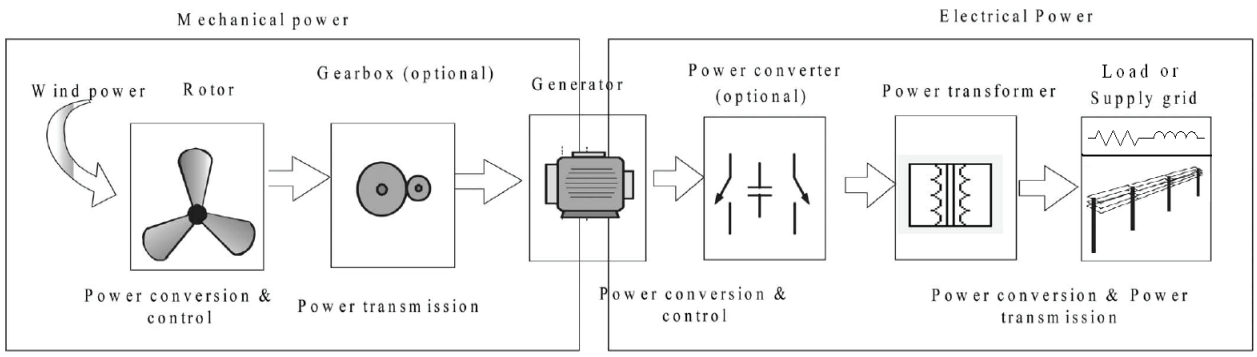

Fig. 2. Component of a wind turbine system.

limitation may be done either by stall control, active stall, or pitch control whose power curves are shown in Fig.3.

It can be seen that the power may be smoothly limited by rotating the blades either by pitch control or active stall control while the power from a stall-controlled turbines show a small overshoot and lower power output for higher wind speed.(Zhe Chen et al, 2009)

All of three methods for wind turbine power limitation usually used in large scale wind turbines, hence the power limitation during higher wind speeds in small scale wind turbines may be done by furling control or soft-stall control.

Many small wind turbines use an upwind rotor configuration with a tail vane for passive yaw control. Typically, the tail vane is hinged, allowing the rotor to furl (turn) in high winds, providing both power regulation and over-speed protection. Most the today's small wind turbines are operated using a variable speed generator. At higher wind speeds, the generated power of the wind turbine can go above the limit of the generator or the wind turbine design. When this occurs, small wind turbines use mechanical control or furling to turn the rotor out of the wind resulting in shedding the aerodynamic power or a steep drop in the power curve. Often, small turbine rotors furl abruptly at a wind speed only slightly above their rated wind speed, resulting in a very "peaky" power curve and poor energy capture at higher wind speeds. This energy loss is compounded by the furling hysteresis, in which the wind speed must drop considerably below the rated wind speed before the rotor will unfurl and resume efficient operation.

One way to improve the performance of furling wind turbines is to design the rotor to furl progressively, causing the power output to remain at or near rated power as the wind speed increases beyond it's rated value. This approach has two drawbacks: wind turbine rotors operating at high furl angles tend to be very noisy and experience high flap loads.

Fig.4 is the free body diagram of the system. It illustrates the simplified description of the furling mechanism. In a normal condition, the effective wind speed $V_{n}=V$ is the useful wind directed to the plane of rotation. The thrust is the force perpendicular to the plane of rotation. It is proportional to the square of the effective wind speed. The in-plane force, $P_{\text {force }}$, which is parallel to the plane of rotation, does not exist in the normal condition. When the wind speed increases, both the thrust and the $P_{\text {force }}$ on the blade create moments due to the offset $d_{1}$ and $d_{2}$. As a result, the angle $\theta$ increases thus reducing the normal component of the wind speed $V_{n}$. As $V_{n}$ decreases, the thrust and the wind energy converted to aerodynamic power also decreases.

The forces contributing to the moment around the pivot point are the thrust and the $P_{\text {force }}$. The thrust can be computed by considering the normal component of the wind speed. 


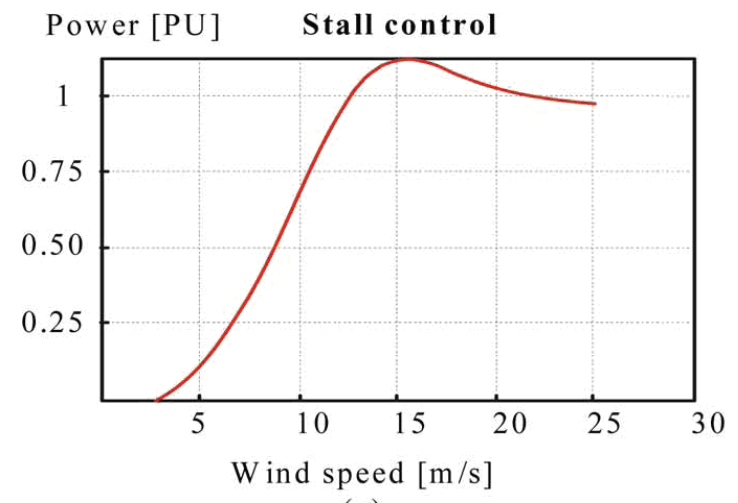

(a)

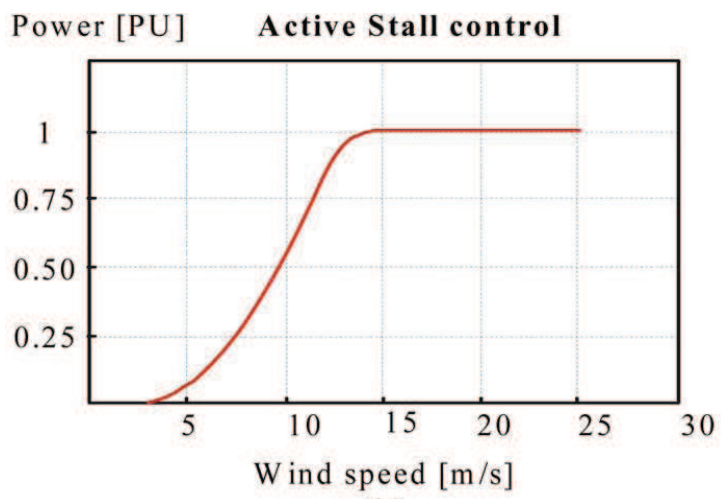

(b)

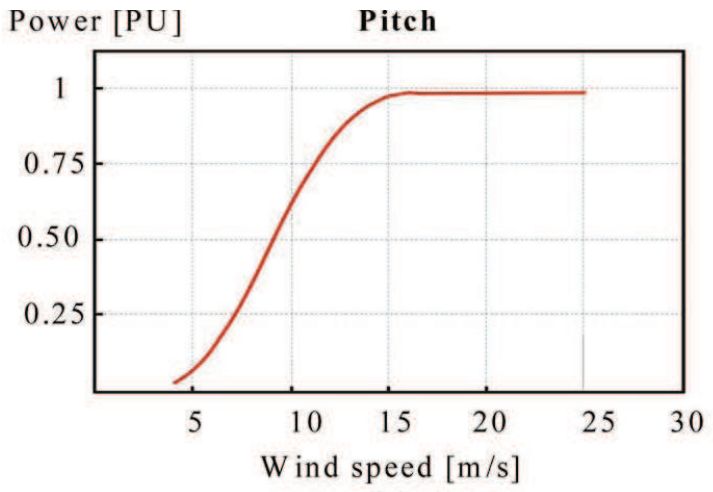

(c)

Fig. 3. Power characteristics of wind turbines. (a)stall control, (b)active stall control, (c)pitch control 


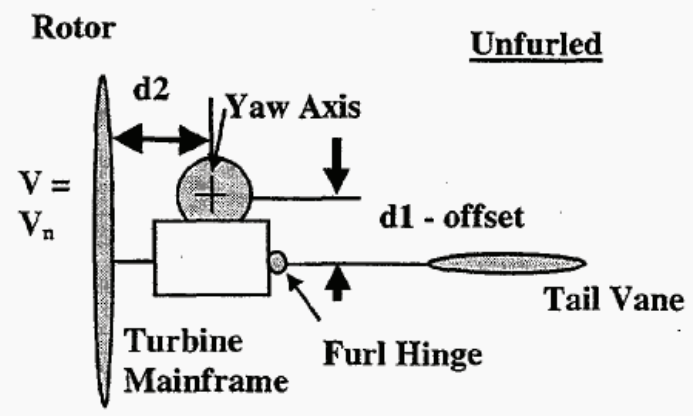

(a) Normal Condition

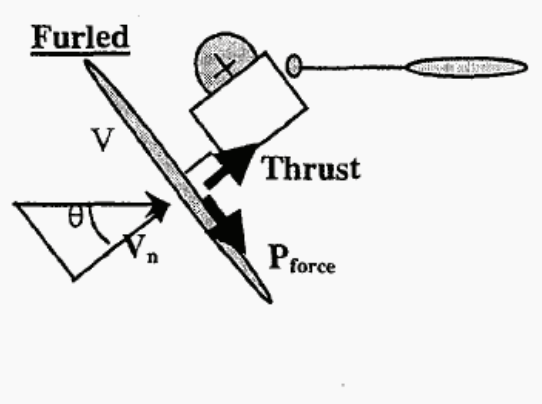

(b) Furling Condition

Fig. 4. Free body diagram of the furling system

$$
\text { Thrust }=0.5 \rho C_{T} A V_{n}^{2}
$$

The furling moment created by the blade can be written as

$$
M_{B}=\text { Thrust } \times d 1+P_{\text {force }} \times d 2
$$

And the restraining moment from the tail vane can be approximately represented by

$$
M_{T}=K 1+K 2 \times \theta
$$

where $\mathrm{K} 1$ and $\mathrm{K} 2$ are the parameters of the wind turbine for the furling mechanism.

The equilibrium is governed by the following equation:

$$
M_{B}-M_{T}=J \theta^{\prime \prime}
$$

where $\mathrm{J}$ is the moment inertia of the turbine with respect to the yaw axis, $\theta$ is the furling angle, and $\theta^{\prime \prime}$ is the acceleration of furling rotation.

Note that manufactured wind turbines use a damper to reduce the furling loop hysteresis. Damping is necessary to keep the wind turbine from cycling or chattering in and out of furling. The damping plus the gyroscopic effect of turning wind turbine blades add to the unproductive time of entering and leaving the furling condition creating a hysteresis during transition. All of these delays reduce the wind turbine energy production.

The soft-stall concept is to control the generator rotations per minute (rpm) and achieve optimum operation over a wide range of rotor rpm. In order to control the generator rpm, the soft-stall concept regulates the stall mode of the wind turbine, thus furling can be delayed in normal operation. Furling is still used in the soft-stall concept during very high winds and emergency conditions. Potential advantages of soft-stall control are listed as follows:

- Delays furling as long as possible, which increases energy production

- Controls the wind turbine rotational speed to achieve the maximum power coefficient

- Operates the wind turbine at a low tip-speed ratio during high wind speeds to reduce noise and thrust loads. (E. Muljadi. et al, 1998 and Bialasiewicz, J.T., 2003)

The only difference between furling and soft-stall control is the addition of the DC-DC converter that allows the power to be controlled. With the DC-DC Converter between the 
rectifier and load, the transmitted power to the load can be controlled according to prescribed power/rpm schedule. Generated power curve for furling and soft stall control methods are shown in Fig.5.

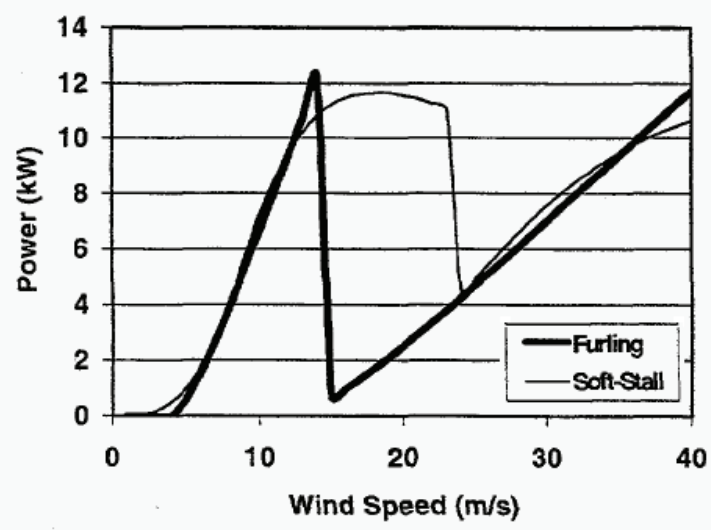

Fig. 5. Generated power for furling and soft-stall control

The two common types of electrical machines used in small scale wind turbines are selfexcited induction generators (SEIG) and permanent magnet synchronous generators (PMSG). In these cases, the common way to convert the low-speed mechanical power to electrical power is a utilizing a gearbox and a SEIG or PMSG with standard speed. The gearbox adapts the low speed of the turbine rotor to the high speed of generators, though the gearbox may not be necessary for multiple-pole generator systems. The generator converts the mechanical power into electrical power.

In the self-excited induction generators, the reactive power necessary to energize the magnetic circuits must be supplied from parallel capacitors bank at the machine terminal. In this case, the terminal voltage or reactive power may not be directly controlled, and the induction generators may suffer from voltage instability problem.

There is considerable interest in the application of the multiple-pole Axial Flux Permanent Magnet Synchronous Generators (AFPMSG) driven by a wind-turbine shaft without gearbox. Small scale wind conversion system may be integrated into loads or power systems with full rated power electronic converters. The wind turbines with a full scale power converter between the generator and load give the added technical performance. Usually, a back-toback voltage source converter (VSC) is used in order to achieve full control of the active and reactive power. But in this case, the control of whole system would be a difficult task. Since the generator has been decoupled from electric load, it can be operated at wide range frequency (speed) condition and maximum power extract.

Fig. 6 shows two most used solutions with full-scale power converters. All two solutions have almost the same controllable characteristics since the generator is decoupled from the load by a dc link.

The configuration shown in Fig.6(a) is characterized by having a gearbox. The wind turbine system with a self-excited induction generator and full rated power electronic converters is shown in Fig.6(a). Multipole systems with the axial flux permanent magnet synchronous generator without a gearbox is shown in Fig.6(b). 

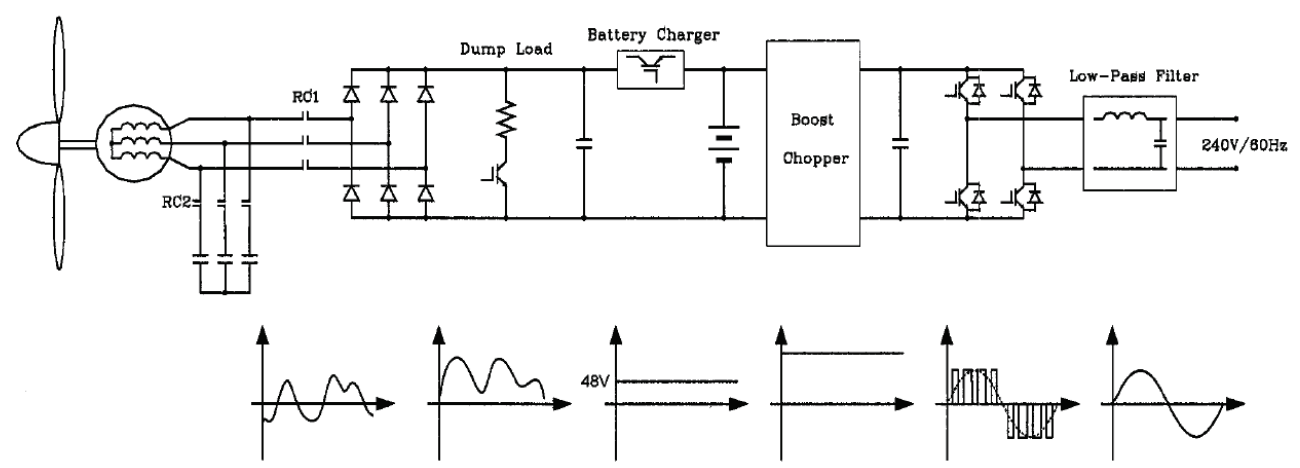

(a)
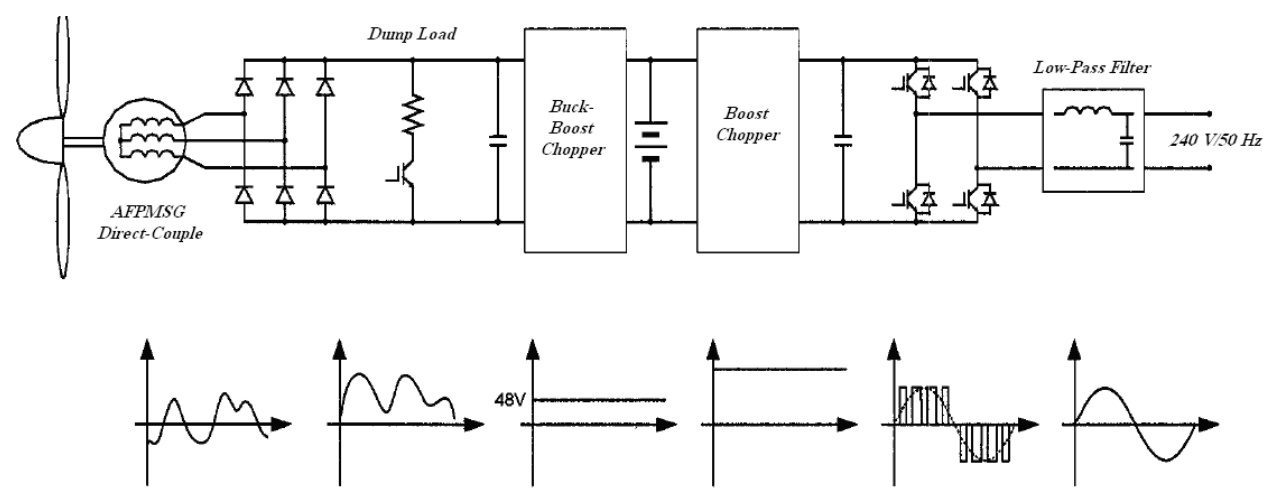

(b)

Fig. 6. Small scale wind generation system. (a)self-excited induction generator with gearbox (b)direct coupled axial flux permanent magnet synchronous generator

\section{Maximum power point tracking systems for wind generators}

Variable-speed wind turbines are able to operate at an optimal rotation speed as a function of the wind speed. The power electronic converter may control the turbine rotation speed to get the maximum possible power by means of a maximum power point tracking (MPPT) algorithm. In this way, it is also possible to avoid exceeding the nominal power if the wind speed increases. At the same time, the dc-link capacitor voltage is kept as constant as possible, achieving a decoupling between the turbine-side converter and the grid-side converter. The grid-connected inverters will inject the active power to the grid with minimum total harmonic distortion (THD) of output current and voltage. The grid voltage and inverter output voltage will be synchronized by zero-crossing circuit.

The rotor efficiency curve $C_{p}(\lambda)$ is a nonlinear function of the TSR, $\lambda$, which is determined by the blade design, and the pitch angle. From Fig.7(a), it is clear that there is a value of $\lambda$ for which $C_{P}$ is maximized, thus maximizing the power for a given wind speed. Because of the 
relationship between $C_{P}$ and $\lambda$, for each wind velocity, there is a turbine speed that gives a maximum output power. The peak power points for various wind speeds are shown in Fig.7(b). Normally, a variable-speed wind turbine follows the $C_{P \max }$ to capture the maximum power up to the rated speed by varying the rotor speed to keep the system at the optimum TSR, $\lambda_{\text {opt }}$. (Zhe Chen et al, 2009)

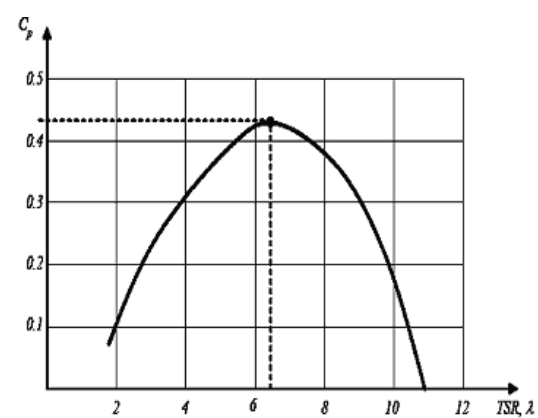

(a)

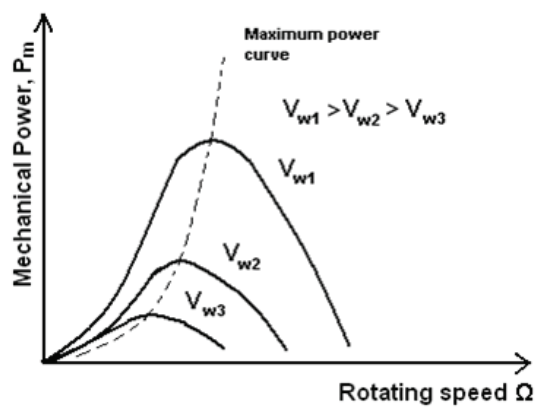

(b)

Fig. 7. (a)relationship between the TSR and the power coefficient. (b)wind turbine $P-\Omega$ characteristics and maximum power curve different wind speeds.

A typical example of the relationship between the wind speed and the power generated by the wind turbine is shown in Fig.8. The blades start to move around $4 \mathrm{~m} / \mathrm{s}$, and optimal aerodynamic efficiency is achieved up to the rated wind speed, about $15 \mathrm{~m} / \mathrm{s}$. Between the rated wind speed and $25 \mathrm{~m} / \mathrm{s}$, the power delivered is limited in order to avoid overloading on the wind turbine system. Above the cutout wind speed, the turbine has to be stopped in order to avoid damages.(Zhe Chen et al, 2009)

Two of the most commonly applied trends in the MPPT processes namely: The tracking method based on the optimum power versus speed characteristic and the perturbation and observation (P\&O) of the output power method.(Ch.Patsios et al, 2008)

During the optimal condition of wind speed, the wind generator may be adjusted to follow the various methods to perform MPPT algorithm that will be summarized as follows.

1. TSR Control: Fig.9 shows this kind of MPPT controller, which needs the wind speed measured by an anemometer. The controller regulates the wind turbine speed to maintain an optimal TSR. However, the accurate wind speed may be difficult to obtain. 
In addition, the use of an external anemometer increases the complexity and cost of the system.

In addition, the use of wind speed sensor to measure the wind speed adds to a system a cost and presents some difficulties in practical implementation. These MPPT methods described in the current literature are too expensive compared with generator whose rated capacity is small.( T.Tafticht et al., 2006)

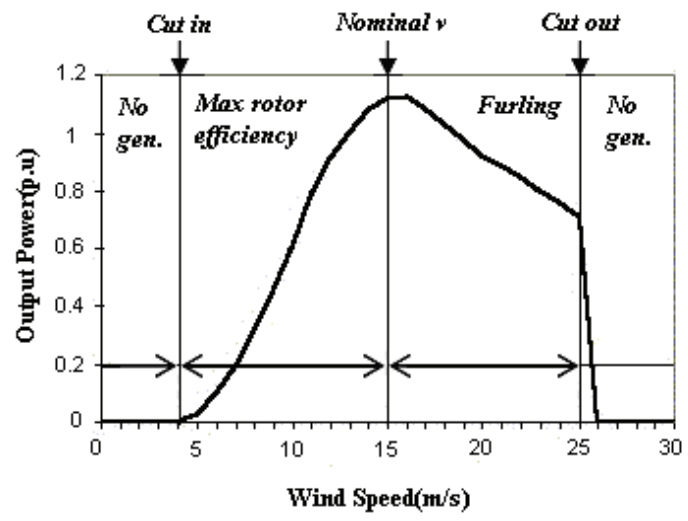

Fig. 8. output power of wind turbine as a function of wind speed.

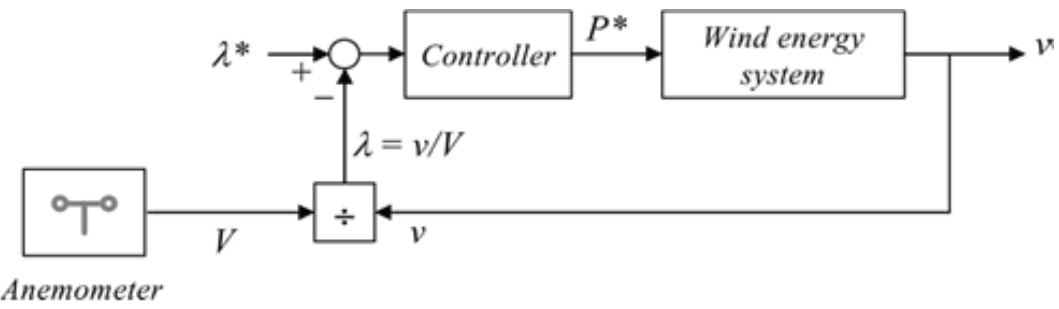

Fig. 9. Block diagram of TSR Control

2. Power Signal Feedback (PSF) Control: This control, depicted in Fig.10, requires the knowledge of the maximum power curves of the turbine, which may be obtained through simulations and practical tests. The speed of the wind turbine is used to select the stored power curve, which gives the target power to be tracked by the system. In many cases, this power curve may be substituted by a predictor or an observer of the wind speed as a function of the power and the wind-turbine speed.(Zhe Chen et al, 2009)

3. Perturbation and observation $(P \mathcal{E} O)$ Control: This MPPT process is based on monitoring the wind-generator (WG) output power using measurements of the WG output voltage and current and directly adjusting the $\mathrm{dc} / \mathrm{dc}$ converter duty cycle according to the result of comparison between successive WG-output-power values. Although the wind speed varies highly with time, the power absorbed by the WG varies relatively slowly, because of the slow dynamic response of the interconnected wind-turbine/generator system. Thus, the problem of maximizing the WG output power using the converter 
duty cycle as a control variable can be effectively solved using the steepest ascent method according to the following control law:
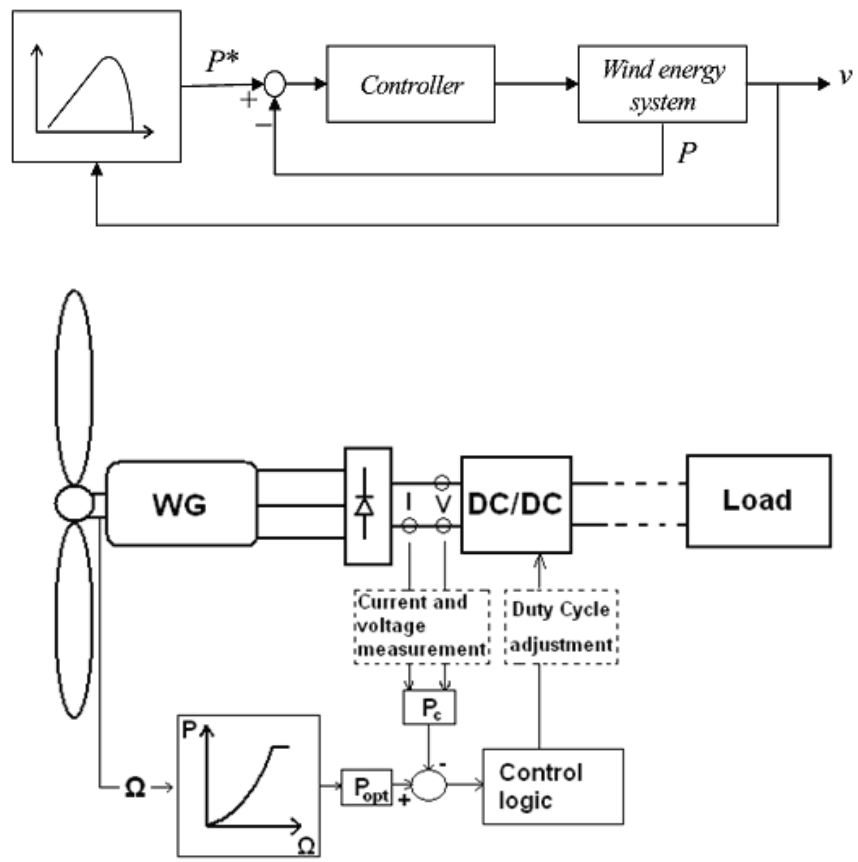

Fig. 10. Block diagram of PSF Control

$$
D_{k}=D_{k-1}+C_{1} \frac{\Delta P_{k-1}}{\Delta D_{k-1}}
$$

where $D_{k}$ and $D_{k-1}$ are the duty-cycle values at iterations $\mathrm{k}$ and $\mathrm{k}-1$, respectively $\left(0<D_{k}<1\right) ; \frac{\Delta P_{k-1}}{\Delta D_{k-1}}$ is the WG power gradient at step $\mathrm{k}-1$; and $C_{1}$ is the step change. Shirazi, M. et al, 2009) A version of the P\&O algorithm is shown in Fig.11

4. Hill Climbing Searching (HCS) Control: In the HCS method, a controller compares the output power of the turbine with the previous power and based on the comparison it controls the load. Using a hill-climbing algorithm the controller tries to extract the maximum power from the wind, while the generator output is observed as the furl angle increase or decreases. In this strategy, the controller will try to adjust the load by measuring the consecutive power and thus the extraction of maximum power from the wind.(Md.Arifujjaman et al., 2005)

When the wind-turbine speed increases, the output power should normally increase as well, otherwise the speed should be decreased (see Fig.12). However, this method could be ineffective for large wind turbines, since the large turbines are difficult to adjust the speed fast. (Zhe Chen et al, 2009) 

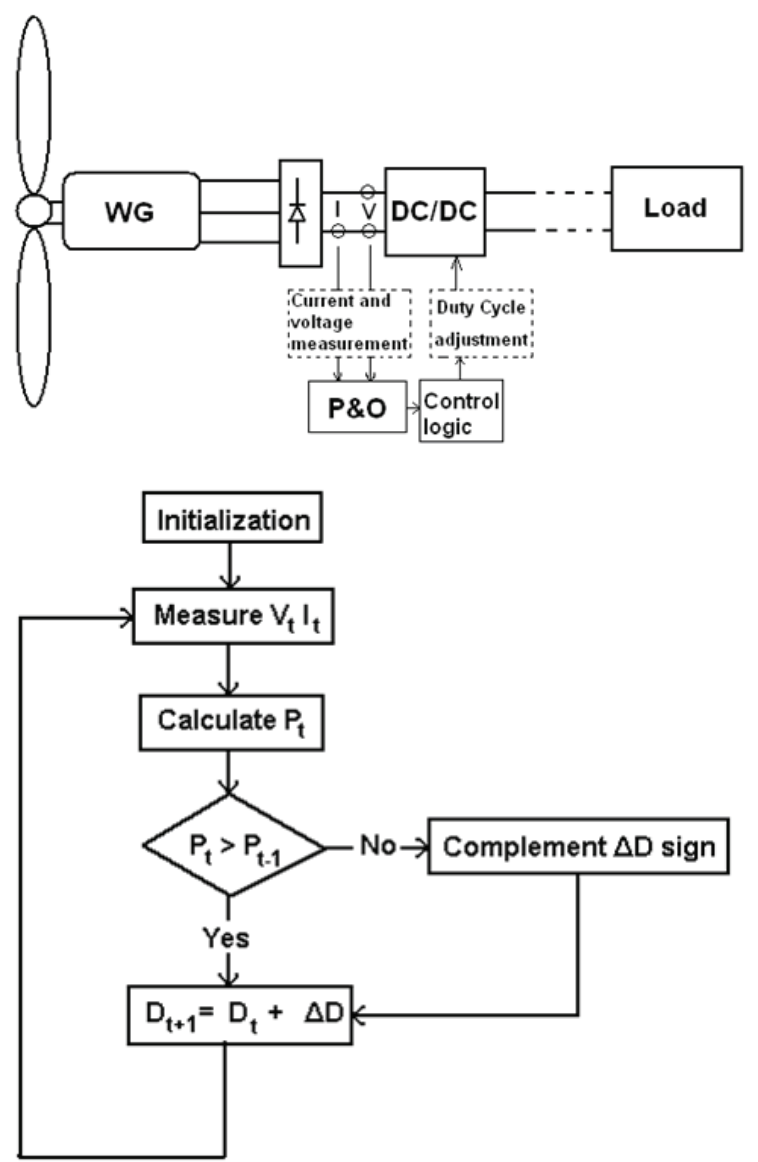

Fig. 11. Block diagram of $\mathrm{P} \& \mathrm{O}$ control

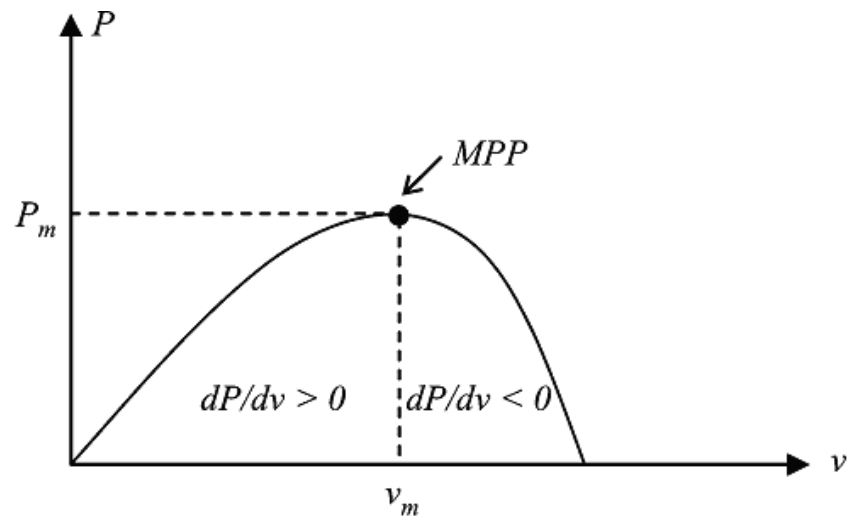

Fig. 12. Block diagram of HCS Control. 
5. MPPT by a maximum-efficiency control and a maximum-torque Control: Based on the turbine characteristics of a selected turbine, the relationship between the optimum generator torque and the generator speed is established. This relationship determines the behaviour of the maximum torque control. For any particular wind speed the generator torque balances the mechanical torque so that they will be equivalent at the optimum operating point. Since the generator torque is controlled in such a way that it tracks the optimum torque curve.

Fig.13 shows the responces of MPPT control. Let it be assumed that the wind speed is $V_{w 3}$ and the generator torque $T_{g}$ balances the mechanical torque $T_{m}$ at the optimum point $\mathrm{A}$ as shown in Fig.13(a). When wind speed changes to $V_{w 2}, T_{m}$ jumps to point $\mathrm{B}$, but $T_{g}$ remains at point $A$. The generator speed increases according to the difference of torque $\left(T_{m}-T_{g}\right)$ (see Fig.13(b)). Then $T_{g}$ increases on the optimum torque curve and $T_{m}$ decreases. After all, they settle down to the optimum torque $T_{\text {opt }}$ for $V_{w 2}$ (point $C$ in Fig. 13(a)). This means that, the generator torque is controlled to track the optimum torque curve for various wind speed by MPPT controller without a wind speed detector.

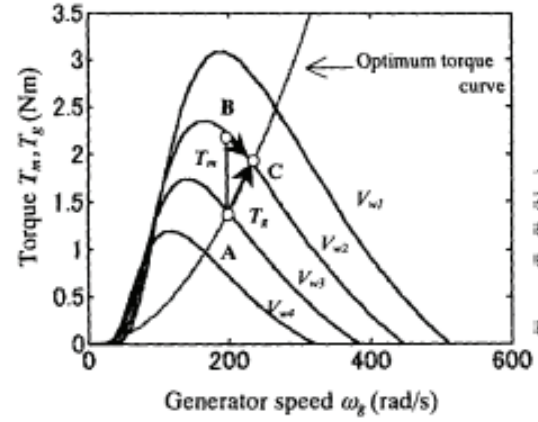

(a)

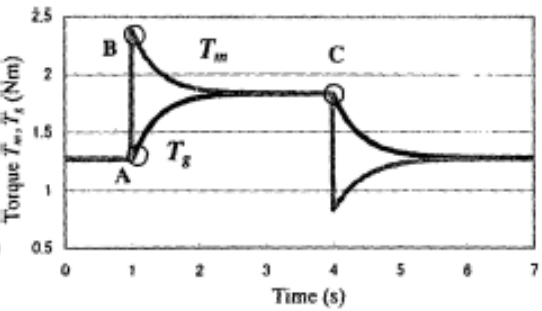

(b)

Fig. 13. (a) Torque-speed curves. (b) Dynamic response of MPPT control.

An advantage of this method is that it does not require a wind speed detector. A drawback of this method is that to select the proportional constant that describes the relationship between the generator torque and speed is based on the turbine characteristics. This dependency hinders its ability to be used for various wind turbines, since different turbines have different characteristics. (Shirazi, M. et al, 2009)

\section{Conclusion}

This chapter has reviewed the small scale wind energy conversion systems. Various arrangements of small scale wind generators with different generators and control systems are described. The power limitation during higher wind speeds in small scale wind turbines may be done by furling control or soft-stall control. The soft-stall control method is better approach than furling control method. In compare with wind generators with gearbox, the main advantages of direct-drive wind generator systems are higher overall efficiency, reliability, and availability due to omitting the gearbox. Considering the improved performance and reduced cost of PM materials over recent years, direct drive AFPMSG have come more attractive for small scale wind generation systems. 
The various MPPT algorithms have described in this chapter. Some methods use the changes in power $(\Delta \mathrm{P})$ and the changes in generator speed $(\Delta \omega)$ to adjust the generator speed towards the optimum operating point. These methods are independent of turbine characteristics, so they are flexible and can be applied to various turbines. However, they would be slower than maximum-torque control method. The maximum-torque control method is fast and efficient, but having prior knowledge of the turbine characteristics is required.

\section{References}

Sathyajith Mathew, Wind Energy Fundamentals, Resource Analysis and Economics, Springer Verlag Berlin Heidelberg, 2006.

Zhe Chen.; Josep M. Guerrero.; Frede Blaabjerg.(2009). A Review of the State of the Art of Power Electronics for Wind Turbines, IEEE TRANSACTIONS ON POWER ELECTRONICS, VOL. 24, NO. 8, pp 1859-1874, AUGUST 2009.

E. Muljadi.; T. Forsyth.; C.P. Butterfield.(1998). SOFT-STALL CONTROL VERSUS FURLING CONTROL FOR SMALL WIND TURBINE POWER REGULATION, Windpower '98 Bakersfield, CA April 27-May 1,1998

E. Muljadi; K. Pierce; P. Migliore; Soft-stall control for variable-speed stall-regulated wind turbines, Journal of Wind Engineering and Industrial Aerodynamics, Volume 85, Issue 3, 24 April 2000, Pages 277-291.

Bialasiewicz, J.T.; Furling control for small wind turbine power regulation, Industrial Electronics, 2003. ISIE '03. 2003 IEEE International Symposium on, pp. 804-809 vol.2, 9-11 June 2003

Patsios, C.; Chaniotis, A.; Kladas, A.; A Hybrid Maximum Power Point Tracking System for Grid-Connected Variable Speed Wind-Generators, Power Electronics Specialists Conference, 2008. PESC 2008. IEEE, pp- 1749 - 1754, 15-19 June 2008

Shirazi, M.; Viki, A.H.; Babayi, O.; A Comparative Study of Maximum Power Extraction Strategies in PMSG Wind Turbine System, : Electrical Power \& Energy Conference (EPEC), 2009 IEEE, pp.1-6, 22-23 Oct. 2009

Arifuijaman, M. Iqbal, M.T. Ouaicoe, J.E. Khan, M.J.; Modeling and control of a small wind turbine , Electrical and Computer Engineering, 2005. Canadian Conference on, pp. 778 - 781, 1-4 May 2005

Tafticht, T.; Agbossou, K.; Cheriti, A.; DC bus control of variable speed wind turbine using a buck-boost converter, Power Engineering Society General Meeting, 2006. IEEE, 5 pp., 16 October 2006

Jia Yaoqin; Yang Zhongqing; Cao Binggang; A new maximum power point tracking control scheme for wind generation, Power System Technology, 2002. Proceedings. PowerCon 2002. International Conference on, pp. 144 - 148 vol.1, 13-17 Oct 2002

Etienne Audierne.; Jorge Elizondo.; Leonardo Bergami.; Humberto Ibarra.; Oliver Probst.; Analysis of the furling behavior of small wind turbines, Applied Energy Volume 87, Issue 7, July 2010, Pages 2278-2292

Molina, M.G.; Mercado, P.E.; A new control strategy of variable speed wind turbine generator for three-phase grid-connected applications, Transmission and Distribution Conference and Exposition: Latin America, 2008 IEEE/PES, pp. 1 - 8, 13-15 Aug. 2008 


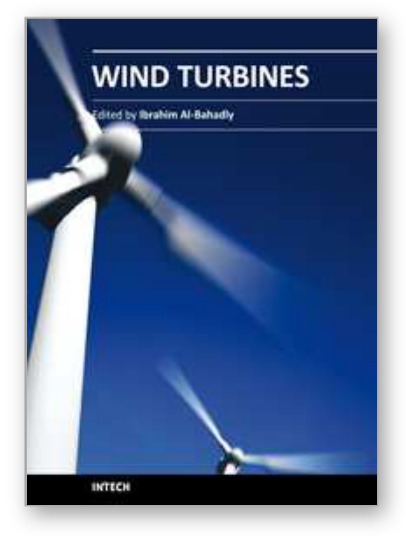

\author{
Wind Turbines \\ Edited by Dr. Ibrahim Al-Bahadly
}

ISBN 978-953-307-221-0

Hard cover, 652 pages

Publisher InTech

Published online 04, April, 2011

Published in print edition April, 2011

The area of wind energy is a rapidly evolving field and an intensive research and development has taken place in the last few years. Therefore, this book aims to provide an up-to-date comprehensive overview of the current status in the field to the research community. The research works presented in this book are divided into three main groups. The first group deals with the different types and design of the wind mills aiming for efficient, reliable and cost effective solutions. The second group deals with works tackling the use of different types of generators for wind energy. The third group is focusing on improvement in the area of control. Each chapter of the book offers detailed information on the related area of its research with the main objectives of the works carried out as well as providing a comprehensive list of references which should provide a rich platform of research to the field.

\title{
How to reference
}

In order to correctly reference this scholarly work, feel free to copy and paste the following:

Mostafa Abarzadeh, Hossein Madadi Kojabadi and Liuchen Chang (2011). Small Scale Wind Energy Conversion Systems, Wind Turbines, Dr. Ibrahim Al-Bahadly (Ed.), ISBN: 978-953-307-221-0, InTech, Available from: http://www.intechopen.com/books/wind-turbines/small-scale-wind-energy-conversion-systems

\section{INTECH}

open science | open minds

\section{InTech Europe}

University Campus STeP Ri

Slavka Krautzeka 83/A

51000 Rijeka, Croatia

Phone: +385 (51) 770447

Fax: +385 (51) 686166

www.intechopen.com

\section{InTech China}

Unit 405, Office Block, Hotel Equatorial Shanghai

No.65, Yan An Road (West), Shanghai, 200040, China

中国上海市延安西路65号上海国际贵都大饭店办公楼405单元

Phone: +86-21-62489820

Fax: +86-21-62489821 
(C) 2011 The Author(s). Licensee IntechOpen. This chapter is distributed under the terms of the Creative Commons Attribution-NonCommercialShareAlike-3.0 License, which permits use, distribution and reproduction for non-commercial purposes, provided the original is properly cited and derivative works building on this content are distributed under the same license. 